J. Lake Sci.(湖泊科学), 2016, 28(4): 868-874

DOI 10. 18307/2016. 0421

(c) 2016 by Journal of Lake Sciences

\title{
东南沿海水库下游地区基于动态模拟的洪涝风险评估
}

\author{
张倩玉, 许有鹏**雷超桂, 王跃峰, 韩龙飞 \\ (南京大学地理与海洋科学学院, 南京 210023)
}

\begin{abstract}
摘 要: 我国东南沿海地区大多为一些中小流域, 这些流域上游多建有水库工程,下游则为人口稠密的平原区, 流域调蓄 能力小, 汇流时间短. 同时, 随着近年来城镇化快速发展, 洪涝风险不断加大. 因此,迫切需要开展水库下游不同暴雨重现 期下的洪涝风险评估研究, 以便为防洪决策提供技术支撑. 为此, 本文利用遥感、GIS、水文水动力学模型等相关技术方 法, 建立洪涝动态模拟模型来评估洪涝危险性; 采用层次分析法和因子叠加法, 从洪涝危险性和洪涝易损性两方面开展 洪涝风险综合评估分析. 研究表明, 通过多学科与多技术手段相结合方法, 来模拟预测不同暴雨重现期洪水动态淹没过 程,再结合相关社会经济属性,可以有效地评估研究区洪涝灾害的风险,从而为水库调度及流域防洪减灾提供有力支撑. 关键词: 水库下游;洪涝;动态模拟; 风险评估;鄞东南平原
\end{abstract}

\section{Risk assessment of flood based on dynamic simulation in downstream of reservoirs in coastal area of southeast China}

\author{
ZHANG Qianyu, XU Youpeng *** LEI Chaogui, WANG Yuefeng \& HAN Longfei \\ ( School of Geographic and Oceanographic Sciences, Nanjing University, Nanjing 210023, P.R.China)
}

\begin{abstract}
The coastal areas of southeast china are characterized by small watersheds with reservoirs in the upstream and high density of population in the downstream, and these watersheds generally have weak ability of storage and short flow concentration time. At the same time, with the rapid development of urbanization, the risk of flood disaster is increasing. So it is urgent to make a research on the risk assessment of flood in downstream of reservoirs with different frequencies of precipitation to provide technology support for decisions on flood prevention and alleviation. Therefore, a flood dynamic simulation model based on remote sensing, GIS, hydrologic and hydraulic model is employed in the hazard risk assessment of flood disaster, as well as analytic hierarchy process and the approach of combining factors are utilized in the comprehensive assessment and analysis of flood risk in views of hazard and vulnerability of flood disasters. This research shows that this simulation model can forecast the dynamic process of flood inundation with different frequencies of precipitation and make an effective assessment of the risk of flood disaster combined with related socioeconomic attributions, so that it can provide strong support for the reservoir dispatching and flood prevention and alleviation.
\end{abstract}

Keywords: Downstream of reservoirs; flood; dynamic simulation; risk assessment; Southeast Yin Plain

我国东南沿海地区多为集水面积较小的中小流域, 易受台风影响而引发极端降雨事件, 导致洪涝灾害 频繁发生. 同时, 该地区上游多由一些水库工程控制, 中下游平原区地势平缓,行洪速度缓慢, 且易受潮位顶 托,排水困难,洪涝交织 ${ }^{\left[{ }^{[1]}\right.}$. 近年来, 该区城镇化快速发展, 人口、经济在空间上高度集聚,增加了生命财产遭 受损害的风险. 因此, 迫切需要开展基于动态模拟的洪涝风险评估研究, 以便为防洪减灾制定合理的对策 措施.

目前洪涝风险评估主要是由洪涝危险性评估和洪涝易损性评估两部分组成 ${ }^{[2-4]}$. 最新发展的洪涝风险 评估方法是指标体系综合评价法 ${ }^{[5-6]}$, 利用 GIS 的空间信息处理功能, 建立洪涝危险性与洪涝易损性评估的

* 国家自然科学基金面上项目 (41371046,41471425)、水利部水利公益专项项目 $(201201072,201501041)$ 、江苏省自 然科学基金项目 (BK20131276) 和江苏省水利科技基金重点项目 (2015003) 联合资助. 2015-07-24 收稿; 201509 - 22 收修改稿. 张倩玉 (1991 ), 女, 硕士研究生; E-mail : zhangqynju@ 163.com.

** 通信作者;E-mail:xuyp305@163.com. 
各指标因子的栅格数据图层, 根据权重对各栅格图层叠加计算得到洪涝风险评估结果 ${ }^{[2-4,6-11]}$. 但运用这种方 法进行洪涝危险性评估时, 由于各指标因子大多是进行宏观处理,例如对历史暴雨洪水资料进行统计分析 时, 选取特征雨量如年最大日雨量、汛期雨量等作为降雨指标 ${ }^{[6-7]}$, 该洪涝危险性评估结果较为粗略, 不能很 好地反映实际的洪涝淹没情况, 借助水文水动力学模型可以解决上述问题, 实现洪涝危险性的动态模拟.

为此, 本文拟通过水文水动力模型的动态模拟来评估洪涝危险性,并结合社会经济易损性指标预测不 同暴雨重现期的洪涝风险. 本研究将以东南沿海地区水库下游的鄞东南平原为例, 借助遥感和 GIS 等技术, 构建水文水动力耦合模型进行洪涝动态模拟, 以探究不同暴雨重现期下的洪涝运动规律, 实现洪涝危险性 评估. 基于 GIS 的栅格叠加计算功能与层次分析法 (AHP), 将洪涝危险性评估结果与社会、经济等易损性指 标因子相结合, 从自然特征和社会经济属性两方面进行洪涝风险综合评估,为水库下游地区防洪减灾对策 提供技术支撑.

\section{1 研究区概况}

鄞东南平原 $\left(29^{\circ} 39^{\prime} \sim 29^{\circ} 59^{\prime} \mathrm{N}, 121^{\circ} 26^{\prime} \sim 121^{\circ}\right.$ $\left.46^{\prime} \mathrm{E}\right)$ 位于我国东南沿海的浙江省宁波市,其总面 积约 $410 \mathrm{~km}^{2}$. 近年来, 该地区城镇化快速发展, 城 镇面积占总面积比例在 1990-2010 年期间增长了 20.9\% (图 1). 区内地势平坦、水系众多, 河网密 布, 主要由前塘河、中塘河、后塘河等河流共同构 成其骨干河网, 内河通过外江与东海相通, 容易受 到潮汐影响, 是典型的感潮平原水网区, 研究区位 于横溪水库、三溪浦水库和东钱湖下游, 其总库容 分别为 $3.9 \times 10^{7} 、 3.31 \times 10^{7}$ 和 $4.43 \times 10^{7} \mathrm{~m}^{3}$, 发挥着防 洪、灌溉、供水等功能, 并实行统一调度 ${ }^{[12]}$. 研究区 易受“梅暴” 和 “台暴” 的影响, 尤其是台风引起的 暴雨具有强度大、雨量大的特点. 在暴雨洪涝期 间, 洪涝水主要通过奉化江、甬江沿岸水闸排出, 一旦遇到天文高潮, 外江潮位升高, 沿江两岸及内 河排涝受阻, 将加剧洪涝灾害. 2013 年 “菲特” 台 风使宁波余姚等地区遭受巨大损失.

\section{2 研究方法及技术路线}

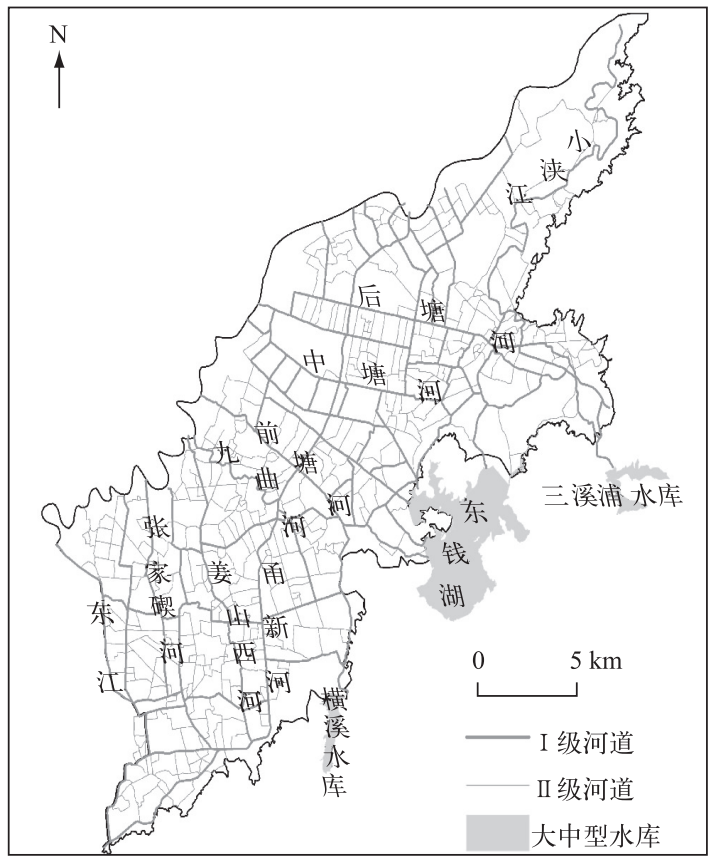

图 1 研究区概况图

Fig. 1 The sketch map of study area

从洪涝危险性和易损性两方面开展洪涝灾害风险评估研究. 在洪涝危险性评估方面, 通过水文分析计 算对不同重现期 $(5 、 10 、 20 、 50$ 和 $100 \mathrm{a}$ ) 暴雨洪水进行预测, 并构建基于 MIKE 模型的一、二维水文水动力耦 合模型, 模拟不同暴雨重现期下洪涝动态淹没过程, 探寻研究区的洪涝运动规律. 本文拟用淹没水深来表征 洪涝发生的强度 ${ }^{[4]}$, 并将其作为洪涝危险性评估指标 ${ }^{[4,13]}$. 洪涝易损性指标选取人口密度和地均 GDP, 结合 淹没水深构建洪港风险评估模型. 在构建洪涝风险评估模型时, 首先利用 Arc GIS 建立淹没水深、人口密度 和地均 GDP 指标的栅格数据图层, 进行标准化处理以消除不同量纲影响, 然后采用层次分析法分别赋以权 重, 根据权重对各指标因子图层进行栅格叠加,得到不同重现期洪涝灾害风险分布图.

\section{3 洪涝动态模拟模型及风险评估模型构建}

研究区上游的横溪水库、三溪浦水库和东钱湖控制研究区上游约 $95 \%$ 的集水面积, 属于典型的水库控 制下平原水网区. 因此, 在进行洪涝淹没模拟研究时, 其重点是水库设计洪水计算以及水库下游平原区洪涝 淹没模拟计算. 


\section{1 不同重现期水库洪水分析}

根据研究区资料情况,采用不同重现期设计暴雨推求设计洪水的方法. 首先,基于各水库集水区内主要 雨量站点长序列暴雨资料, 通过加权平均法求得各流域不同地区的各历时平均面雨量, 暴雨历时选取 $1 、 6$ 、 24 和 $72 \mathrm{~h}$, 然后通过频率计算求得各历时不同重现期 ( 5、10、20、50 和 $100 \mathrm{a}$ ) 的设计暴雨. 最后,对不同重现 期设计暴雨按照该地区典型的暴雨过程进行时空分配,求得不同重现期设计暴雨过程 ${ }^{[14-15]}$. 在计算设计洪 水时, 首先通过新安江三水源模型进行水库上游流域产汇流计算, 得到人库流量, 再根据水库调度规则进行 调洪演算, 求出设计洪水过程. 在确定新安江模型参数时, 具有明确物理意义的参数是从遥感影像图上获取 下垫面特性进行推求而确定, 其他参数主要参照本区及邻近地暴雨洪水过程资料率定求得 ${ }^{[7]}$.

\section{2 水库下游洪涝动态模拟模型构建}

洪涝动态模拟模型构建是基于遥感和 GIS 空间分析, 运用 MIKE - 二维水文水动力耦合模型来动态模 拟不同暴雨重现期洪水的淹没过程,模型中所输人的降雨、水位数据来源于水雨情信息系统. 洪涝动态模拟 模型的构建主要有以下几个部分: (1) 采用 MIKE 11 模型中的降雨径流模型 NAM 计算水库下游的平原区产 流. 由于研究区是典型的平原河网区, 无法划分明确的集水范围, 因此, 基于实际河网概化后的骨干河道并 结合地形、土地利用类型等因素将研究区划分为多个产流小区, 根据就近汇流和按河长比例权重分配的原 则将计算所得的各产流小区的产流量以旁侧人流的形式分配到 MIKE 11 河网文件中的相应河段; (2) 采用 MIKE 11 模型模拟河网水位、流量过程. 基于概化后的骨干河道,建立相应的河网文件与河道断面文件. 模 型的人流除平原区及少量区间产流外,还包括研究区上游水库 (横溪水库、三溪浦水库和东钱湖) 的出库流 量. 考虑到洪涝期间潮位对内河水位的顶托作用，下游选用研究区常用的最大可能的潮位过程,即 “桑美”台 风的潮位过程线作为下边界条件; (3) 运用 MIKE 21 模型模拟洪水的淹没过程. 考虑到在快速城镇化过程中 下垫面变化会导致洪涝过程变化, 而通过设定不同鋉率值可以反映土地利用情况, 因此, 本研究利用遥感影 像进行下垫面信息识别, 并参考邻近地区研究资料先设定初始地面鋉率参数, 然后在模型率定时根据实际 水位过程和水位特征值进行相应调整; (4) 利用 MIKE FLOOD 模型采用侧向连接的方式使一维模型 (MIKE 11 ) 和二维模型 (MIKE 21) 耦合, 实现在水位高于堤岸时洪水从河道向洪水泛滥区漫流的模拟.

采用 2012 年 8 月 1-12 日鄞东南平原遭遇的“苏拉”、“海葵”双台风期间降雨水位及潮位资料对模型 进行参数率定, “苏拉” 台风期间河道水位增加, 但平原区未受淹, 而 “海葵” 台风期间洪水在平原区漫流, 因 此利用“苏拉” 台风降雨水位资料对 NAM 及 MIKE 11 模型进行率定, 利用 “海葵” 台风降雨水位数据对 MIKE 21 模型进行率定. 将分别位于鄞东与鄞南地区的代表水位站五乡站和姜山站对这两场台风的模拟水 位和实测水位过程线进行对比, 除了五乡站的 “苏拉” 台风模拟水位过程线的确定性系数为 0.85 , 其余均达 0.90 以上,平均水位误差均小于 $10 \%$,模拟结果较为可靠.

\section{3 洪涝风险评估模型构建}

选用淹没水深作为洪涝危险性指标、人口密度 $\left(\right.$ 人 $\left./ \mathrm{km}^{2}\right)$ 和地均 $\operatorname{GDP}\left(\right.$ 万元 $\left./ \mathrm{km}^{2}\right)$ 作为洪涝易损性指标 构建洪涝风险评估模型, 从自然特征和社会经济属性的角度综合考虑洪涝灾害风险的影响因素,计算不同 重现期暴雨的研究区洪涝风险分布情况及不同区域洪涝风险值的大小. 利用 ArcGIS 建立淹没水深、人口密 度、地均 GDP 等指标的栅格图层, 其中淹没水深为洪涝动态模拟模型计算的洪水历时最大淹没深度, 每个栅 格单元都有各自的淹没水深值; 人口密度和地均 GDP 均以镇区、街道为单位对栅格图层进行赋值, 数据来源 于相关统计年鉴 ${ }^{[16-17]}$. 对各指标的栅格图层进行标准化处理后, 各栅格单元取值范围为 $0 \sim 1$. 参考该地区相 关研究资料 ${ }^{[3,7]}$, 采用层次分析法确定淹没水深、人口密度和地均 GDP 三项指标的权重. 最后根据权重进行 栅格图层的叠加计算,得到不同暴雨重现期情形下的洪涝风险分布图.

\section{4 模拟结果讨论}

\section{1 水库设计洪水分析与计算}

首先, 根据水库上游长序列暴雨资料,通过频率计算分析求得各水库不同重现期设计暴雨及其过程. 然 后, 采用新安江三水源模型分别对横溪水库、三溪浦水库、东钱湖进行洪水分析与计算, 最后经过水库调洪演 算计算出水库出流过程, 并将其作为洪涝动态模拟模型的人流边界条件. 水库设计洪水计算结果如表 1 所示. 
表 1 水库设计洪水计算结果

Tab. 1 Calculation results of reservoir designed flood

\begin{tabular}{|c|c|c|c|c|c|c|c|c|c|c|}
\hline \multirow[b]{2}{*}{ 水库/湖泊 } & \multicolumn{2}{|c|}{$5 \mathrm{a}$ 一遇 } & \multicolumn{2}{|c|}{$10 \mathrm{a}$ 一遇 } & \multicolumn{2}{|c|}{$20 \mathrm{a}$ 一遇 } & \multicolumn{2}{|c|}{$50 \mathrm{a}$ 一遇 } & \multicolumn{2}{|c|}{$100 \mathrm{a}$ 一遇 } \\
\hline & $\begin{array}{c}\text { 人库洪 } \\
\text { 峰流量/ } \\
\left(\mathrm{m}^{3} / \mathrm{s}\right)\end{array}$ & $\begin{array}{c}\text { 出库洪 } \\
\text { 峰流量/ } \\
\left(\mathrm{m}^{3} / \mathrm{s}\right)\end{array}$ & $\begin{array}{c}\text { 人库洪 } \\
\text { 峰流量/ } \\
\left(\mathrm{m}^{3} / \mathrm{s}\right)\end{array}$ & $\begin{array}{c}\text { 出库洪 } \\
\text { 峰流量/ } \\
\left(\mathrm{m}^{3} / \mathrm{s}\right)\end{array}$ & $\begin{array}{c}\text { 人库洪 } \\
\text { 峰流量/ } \\
\left(\mathrm{m}^{3} / \mathrm{s}\right)\end{array}$ & $\begin{array}{c}\text { 出库洪 } \\
\text { 峰流量/ } \\
\left(\mathrm{m}^{3} / \mathrm{s}\right)\end{array}$ & $\begin{array}{c}\text { 人库洪 } \\
\text { 峰流量/ } \\
\left(\mathrm{m}^{3} / \mathrm{s}\right)\end{array}$ & $\begin{array}{c}\text { 出库洪 } \\
\text { 峰流量/ } \\
\left(\mathrm{m}^{3} / \mathrm{s}\right)\end{array}$ & $\begin{array}{c}\text { 人库洪 } \\
\text { 峰流量/ } \\
\left(\mathrm{m}^{3} / \mathrm{s}\right)\end{array}$ & $\begin{array}{c}\text { 出库洪 } \\
\text { 峰流量/ } \\
\left(\mathrm{m}^{3} / \mathrm{s}\right)\end{array}$ \\
\hline 横溪水库 & 220.95 & 131.28 & 281.36 & 188.67 & 341.79 & 241.78 & 400.13 & 310.38 & 484.25 & 352.78 \\
\hline 东钱湖 & 245.64 & 121.58 & 377.34 & 145.90 & 456.79 & 172.36 & 558.94 & 213.79 & 637.75 & 249.80 \\
\hline 三溪浦水库 & 319.44 & 220.54 & 409.53 & 311.25 & 498.65 & 386.35 & 596.44 & 470.51 & 683.40 & 546.13 \\
\hline
\end{tabular}

\section{2 不同重现期淹没范围情况}

应用 MIKE 一、二维水文水动力耦合模型对鄞 东南平原区不同重现期暴雨 $(5 、 10 、 20 、 50$ 和 100 a) 进行淹没模拟,提取各淹没历时水深文件,在 Arc GIS 进行栅格叠加后, 利用 ENVI 软件提取最大水 深作为最终的淹没深度, 淹没结果如图 2 所示. 从 淹没范围空间分布上看,淹没区主要位于研究区中 部地势低洼的东吴镇、五乡镇、云龙镇和姜山镇等 乡镇地区,在遭遇 $5 \mathrm{a}$ 一遇洪水时,这些地区受淹范 围很大,而中心城区、钟公庙街道和小港街道等地 区淹没面积较小. 这主要是因为,一方面, 乡镇地区 地面高程普遍较低;另一方面,这些地区水系发达, 且河道两边堤岸较低,在洪水期间河道中的水流容 易向平原区漫流. 尤其是东吴镇与横溪镇, 地处水 库下游, 受水库泄流影响, 洪涝期间淹没较为严重. 而中心城区高程普遍加高,并且防洪排涝工程措施 比乡镇更为完善. 因此, 与乡镇相比, 受洪灾影响 较小.

由不同暴雨重现期下洪水淹没面积及淹没面 积占全区比例可以看出 (表 2), 当暴雨重现期为 5 $\mathrm{a}$ 一遇时,五乡镇、东吴镇和云龙镇等乡镇区已经受 到淹没; 当暴雨重现期达 $100 \mathrm{a}$ 一遇时,淹没面积达 到全区的 $46.47 \%$. 因此, 总的来说, 鄞东南平原受 洪涝灾害严重影响,尤其是对于洪水淹没严重的乡 镇区,一方面要做好防汛工程的建设,另一方面在 灾害发生时能够做好合理的抢险救灾方案,尽量减 少灾害损失.

\section{3 洪涝风险动态评估分析}

为满足水库调度中应对不同风险等级洪水变 化特性的需要, 同时也为能够提前做好人员和财产 物资转移方案提供技术支持, 需要分析洪水动态过 程及其风险变化, 以便从全局掌握区域内洪水运动 的变化规律. 在 2013 年“海葵”台风期间,该地区遭

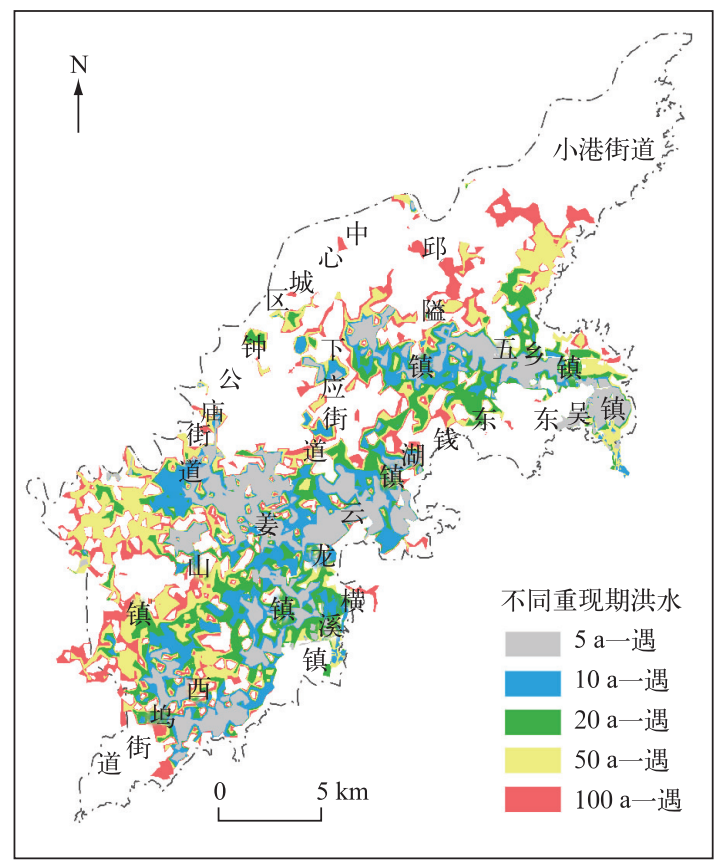

图 2 研究区不同重现期洪水淹没范围

Fig. 2 Inundation areas of different frequencies of storm

表 2 不同暴雨重现期洪水淹没面积及占全区比例

Tab.2 Inundation areas and its percentage of different frequencies of storm

\begin{tabular}{ccc}
\hline 暴雨重现期 & 淹没面积 $/ \mathrm{km}^{2}$ & 淹没面积占全区比例 $/ \%$ \\
\hline $100 \mathrm{a}$ 一遇 & 190.52 & 46.47 \\
$50 \mathrm{a}$ 一遇 & 163.95 & 39.99 \\
$20 \mathrm{a}$ 一遇 & 116.93 & 25.52 \\
$10 \mathrm{a}$ 一遇 & 78.51 & 19.15 \\
$5 \mathrm{a}$ 一遇 & 43.43 & 10.60 \\
\hline
\end{tabular}


遇接近 $50 \mathrm{a}$ 一遇洪水, 其实际洪水淹没情况与本次水文分析成果及模型模拟结果基本一致. 因此, 以 $50 \mathrm{a}$ 一 遇洪水为例, 从发生淹没时开始计算, $24 \mathrm{~h}$ 具体淹没情况表明,开始时,主干河道的水流向堤岸两边漫流,接 着向四周扩散. 最先出现淹没的地方为地势低洼的东吴镇、五乡镇、钟公庙街道和云龙镇, 这些区域局部地 区的高程较低, 其中东吴镇受三溪浦水库泄流影响, 淹没最为严重. 随着时间的推移, 洪水淹没深度与范围
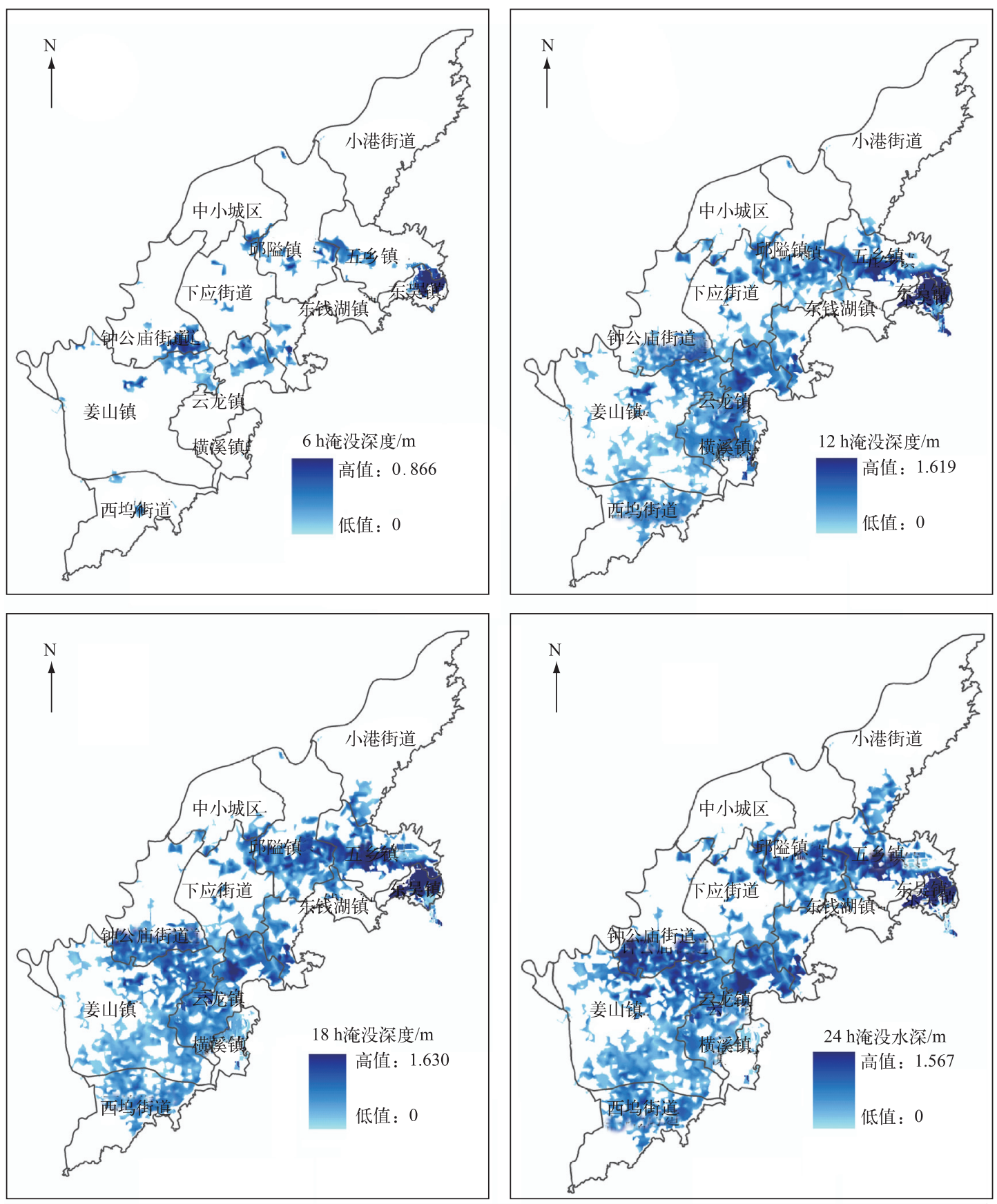

图 3 研究区 $50 \mathrm{a}$ 一遇洪水淹没 $24 \mathrm{~h}$ 动态图

Fig. 3 24-hour dynamic inundation during the flood with 50-year return period 
均呈增加的态势, 淹没 $12 \mathrm{~h}$ 之后, 淹没面积增加 的速度减慢,而淹没水深不断增加. 第 $24 \mathrm{~h}$ 淹没 深度为 $0 \sim 1.5 \mathrm{~m}$, 其中三溪浦水库下游的东吴镇 局部地区淹没水深超过 $1 \mathrm{~m}$. 从整体上看,整个洪 水淹没过程是从最先开始淹没的东吴镇、五乡镇、 邱险镇和云龙镇分别向四周扩散. 洪水淹没空间 分布较为集中,主要分布在两个片区,其中一个片 区由东吴镇、五乡镇和邱险镇组成, 呈条带状, 另 一个片区在研究区的南部. 从淹没深度上看,研究 区内有 $28.31 \mathrm{~km}^{2}$ 的区域淹没深度达 $0.5 \sim 1.0 \mathrm{~m}$; $3.95 \mathrm{~km}^{2}$ 的区域淹没深度大于 $1 \mathrm{~m}$,主要分布在东 吴镇 (图 3).

通过上述洪涝风险评估模型进行不同等级洪 涝风险值计算,得到该地区的洪涝灾害风险分布 (图 4), 洪水风险值的取值范围为 $0 \sim 1$, 洪涝灾害 风险越大,其数值越高. 东吴镇、五乡镇的中部地 区、邱险镇的南部地区、钟公庙街道与姜山镇的交 界处以及云龙镇是受洪涝淹没影响显著的区域. 叠加上社会经济指标后,其洪涝风险值大于 0.4 , 其中三溪浦水库下游的东吴镇洪涝风险值高于 0.5. 中心城区在遭遇 $50 \mathrm{a}$ 一遇洪水的情形下淹 没范围较小,仅靠近邱隘镇的地方有部分淹没,但 其洪涝风险值大于 0.35 (图 4), 仍然比某些地区

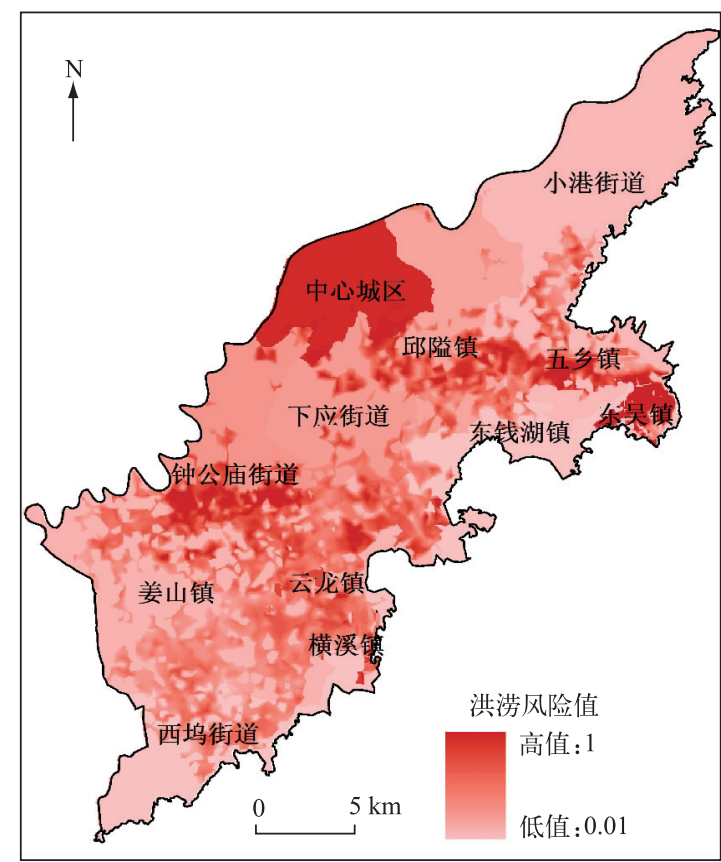

图 4 研究区 $50 \mathrm{a}$ 一遇洪涝风险分布

Fig.4 Distribution of flood risk in the flood with 50-year return period 高, 这主要是因为中心城区作为人口、产业、经济最密集的地区，一旦受到洪涝干扰,其损失比其他地区大得 多,因此其洪涝灾害易损值大,洪涝灾害风险值是由灾害易损性主导的.

\section{5 结语}

通过水文分析与计算进行不同重现期暴雨洪水预测, 基于遥感与 GIS 技术构建水文水动力耦合模型, 预测不同暴雨重现期下研究区洪涝淹没情况, 实现该地区暴雨洪涝过程动态模拟, 并结合社会经济指标进 行洪涝风险评估.

与以往的洪涝风险评估相比, 本文通过洪涝动态模拟实现对洪涝灾害危险性的动态评估分析, 并将其 作为洪涝风险评估的重要组成部分, 以便于掌握洪水风险空间分布特征及其动态变化,也有利于洪水风险 图动态更新. 洪涝动态模拟为洪涝风险评估提供有力支撑,进行不同工况与不同暴雨重现期情形下的洪涝 动态模拟,可全面了解不同情况下洪涝淹没具体过程与结果, 以便提前准备好救灾抢险方案, 同时通过水库 水情信息综合模拟与风险分析, 可动态评估洪水风险状况及淹没情况, 从而为水库下游防洪减灾以及水库 调度的决策制定提供支持.

\section{6 参考文献}

[ 1 ] Xu Youpeng, Ge Xiaoping, Zhang Lifeng et al. Research of flood-inundated simulation on flood plain in coastal medium and small basins of Southeast of China. Geographical Research, 2005, 24(1) : 38-45(in Chinese with English abstract). [许有鹏, 葛小平, 张立峰等. 东南沿海中小流域平原区洪水淹没模拟. 地理研究, 2005, 24(1): 38-45.]

[ 2 ] Zou Q, Zhou JZ, Zhou C et al. Comprehensive flood risk assessment based on set pair analysis-variable fuzzy sets model and fuzzy AHP. Stochastic Environment Research and Risk Assessment, 2013, 27(2) : 525-546.

[ 3 ] Yu Mingjin, Xu Youpeng, Wang Liuyan. Analysis of flood risk of small and medium-sized basins in southeast China under the impacts of urbanization: a case study of Yongcaopu area. Journal of Natural Disasters, 2013, 22(4) : 108-113(in Chi- 
nese with English abstract). [余铭婧, 许有鹏, 王柳艳. 城市化影响下东南沿海中小流域洪灾风险分析一一用曹 浦地区为例. 自然灾害学报, 2013, 22(4): 108-113.]

[ 4 ] Zhou Chenghu, Wan Qing, Huang Shifeng et al. A GIS-based approach to flood risk zonation. Acta Geographica Sinica, 2000, 55(1): 15-24(in Chinese with English abstract). [周成虎, 万庆, 黄诗峰等. 基于 GIS 的洪水灾害风险区划 研究. 地理学报, 2000, 55(1): 15-24.]

[ 5 ] Liu Jiafu, Zhang bai. Progress of rainstorm flood risk assessment. Scientia Geographica Sinica, 2015, 35(3): 346-351 (in Chinese with English abstract). [刘家福, 张柏. 暴雨洪灾风险评估研究进展. 地理科学, 2015, 35(3) :346-351.]

[ 6 ] Li Guofang, Zheng Linyu, Tong Yiyi et al. Effect evaluation of urbanization on flood risk in the Yangtze River Delta. Resources and Environment in the Yangtze Basin, 2013, 22(3): 386-391 (in Chinese with English abstract). [李国芳, 郑 玲玉，童奕懿等. 长江三角洲地区城市化对洪灾风险的评价. 长江流域资源与环境，2013，22(3): 386-391.]

[ 7 ] Xu Youpeng, Pan Guangbo, Zhou Feng et al eds. Flood risk under watershed urbanization. Nanjing: Southeast University Press, 2012: 133-183 (in Chinese). [许有鹏, 潘光波, 周峰等. 流域城市化与洪涝风险. 南京: 东南大学出版社, 2012: 133-183.]

[ 8 ] Geng Huantong, Wu Zhengxue, Ji Haojun et al. GIS-based risk zonation of flood disasters in Jiading district of Shanghai. Journal of Catastrophology, 2015, 30(1): 96-101 (in Chinese with English abstract). [ 耿焕同, 吴正雪, 计浩军等. 基 于 GIS 的上海市嘉定区暴雨积涝灾害风险区划研究. 灾害学, 2015, 30(1): 96-101.]

[ 9 ] Liu Jiafu, Li Jing, Liu Jing et al. Integrated GIS/AHP-based flood risk assessment: a case study of Huaihe River Basin in China. Journal of Natural Disasters, 2008, 17(6) : 110-114( in Chinese with English abstract). [刘家福, 李京, 刘荆 等. 基于 GIS/AHP 集成的洪水灾害综合风险评价——以淮河流域为例. 自然灾害学报, 2008,17 (6): 110-114.]

[10] Wang YM, Li ZW, Tang ZH et al. A Gis-based spatial multi-criteria approach for flood risk assessment in the Dongting Lake Region, Hunan, Central China. Water Resources Management, 2011, 25(13) : 3465-3484.

[11] Li Lintao, Xu Zongxue, Pang Bo et al. Flood risk zoning in China. Journal of Hydraulic Engineering, 2012, 43(1) : 2230 (in Chinese with English abstract). [李林涛, 徐宗学, 庞博等. 中国洪灾风险区划研究. 水利学报, 2012, 43 (1) : 22-30.]

[12] Ningbo Yinzhou district water conservancy annals compilation committee. Beijing: Zhonghua Book Company, 2009(in Chinese). [《宁波市鄞州区水利志》编纂委员会. 宁波市鄞州区水利志. 北京: 中华书局, 2009.]

[13] De Moel, Aerts JCJH. Effect of uncertainty in land use, damage models and inundation depth on flood damage estimates. Natural Hazards, 2011, 58(1): 407-425.

[14] Liang Zhongmin, Zhong Ping'an, Hua Jiapeng eds. Hydrologic and hydraulic calculation( second edition). Beijing: China Water \& Power Press, 2008: 65-99 (in Chinese). [ 梁忠民, 钟平安, 华家鹏. 水文水利计算(第 2 版). 北京: 中国水 利水电出版社, 2008: 65-99.]

[15] Liu Guangwen ed. Hydrologic analysis and compulation. Beijing: Water Resources and Electric Power Press, 1989: 105146(in Chinese). [刘光文. 水文分析与计算. 北京: 水利电力出版社, 1989: 105-146.]

[16] Ningbo Municipal Statistics Bureau, Survey Office of the National Bureau of Statistics in Ningbo. Ningbo Statistical Yearbook-2013. Beijing: China Statistics Book, 2013(in Chinese). [宁波市统计局, 国家统计局宁波调查队. 宁波统计 年鉴一2013. 北京: 中国统计出版社, 2013.]

[17] Ningbo Yinzhou district People's goveronment office of local chronicles. Yinzhou Yearbook (2013). Zhejiang: Zhejiang People's Publishing House, 2014(in Chinese). [宁波市鄞州区人民政府地方志办公室. 鄞州年鉴(2013). 杭州: 浙 江人民出版社, 2014.] 